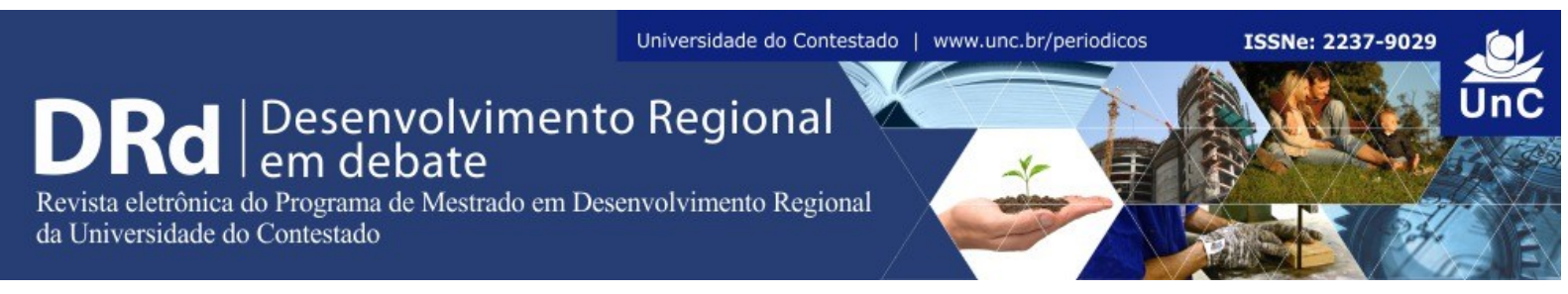

\title{
AGRICULTURA FAMILIAR E AUTONOMIA: A CONSTRUÇÃO SOCIAL E POLÍTICA DE MERCADOS NO NOROESTE GAÚCHO
}

\author{
Vanderlei Franck Thies ${ }^{1}$ \\ Marcelo Antonio Conterato ${ }^{2}$
}

\begin{abstract}
RESUMO
As formulações teóricas mais recentes evidenciam a importância da relação dos agricultores familiares com os mercados, tanto para sua reprodução social, como para as dinâmicas de desenvolvimento rural. O conteúdo da relação dessa categoria social com os mercados pode colocar esses sujeitos numa posição de maior ou menor autonomia, ampliando ou restringindo as possibilidades de sua reprodução. $O$ presente artigo se inscreve teoricamente no debate relacionado ao processo de mercantilização da agricultura e tem por objetivo analisar as implicações que a inserção nos mercados institucionais gera nas dinâmicas de venda da produção e na autonomia comercial dos agricultores. Procura-se identificar em que medida o ingresso no Programa de Aquisição de Alimentos - PAA se associa com a ampliação, ou redução, nas taxas de uso dos demais canais de comercialização, buscando verificar se as mudanças transcorridas apontam para a ampliação, ou diminuição, da autonomia comercial dos agricultores. Foi realizado estudo de caso em duas cooperativas no noroeste gaúcho, combinando aspectos qualitativos e quantitativos, utilizando questionários, entrevistas em profundidade e observação participante para a produção de dados primários. Os resultados evidenciam diferentes efeitos do programa nas duas cooperativas em relação à autonomia dos agricultores.
\end{abstract}

Palavras-chave: Agricultura familiar. Autonomia comercial. Mercados institucionais.

\section{FAMILY FARMER AND AUTONOMY: THE SOCIAL AND POLITICAL CONSTRUCTION OF MARKETS IN NORTHEASTERN RIO GRANDE DO SUL}

\begin{abstract}
Recent theoretical formulations have highlighted how important are the connections of family farmers with the markets, as much for their social reproduction as for the dynamics of rural development. The substance of the relationship between this social category and the markets may place these subjects at a more or less autonomous position, either expanding or limiting

\footnotetext{
${ }^{1}$ Engenheiro Agrônomo (UFPel). Mestre e Doutorando em Desenvolvimento Rural no PGDR/UFRGS. Membro do Grupo de Estudos e Pesquisas Agricultura Familiar e Desenvolvimento Rural - GEPAD. E-mail: vftc3@yahoo.com.br

2 Geógrafo (UFSM). Mestre e Doutor em Desenvolvimento Rural (PGDR/UFRGS), professor da UFRGS no Departamento de Economia e Relações Internacionais (DERI) e do Programa de Pós-Graduação em Desenvolvimento Rural (PGDR). Membro do Grupo de Estudos e Pesquisas Agricultura Familiar e Desenvolvimento Rural - GEPAD. E-mail: marcelo.conterato@ufrgs.br
}

DRd - Desenvolvimento Regional em debate (ISSNe 2237-9029)

v. 7, n. 1, p. 51-74, maio 2017. 
the possibilities for their reproduction. The present article is aligned with the theoretical debate on the commodification of agriculture and aims to analyse the consequences of farmers' entry in the institutional markets on the dynamics of selling their produce and on their commercial autonomy. It seeks, particularly, to ascertain to what extent the entry in the Food Procurement Program (FPP) is connected to increase or reduction in the rates of use of other marketing channels, and if the changes occurred represent either an increase or a decrease in the commercial autonomy of farmers. A case study was conducted on two agricultural cooperatives in the north-eastern region of Rio Grande do Sul, which combined qualitative and quantitative analyses and resorted to questionnaires, in-depth interviews and participant observation for collecting primary data. Findings show distinct impacts of the program on the two cooperatives, regarding the autonomy of the farmers.

Keywords: Family farming. Comercial autonomy. Institutional markets.

\section{INTRODUÇÃO}

O presente artigo se inscreve teoricamente no debate relacionado ao processo de mercantilização da agricultura. O objeto de análise é o Programa de Aquisição de Alimentos PAA e o estudo visa identificar a relação entre essa política pública e a variação na autonomia comercial dos agricultores familiares.

O Brasil tornou-se referência internacional de apoio à agricultura familiar devido às políticas públicas adotadas nas duas últimas décadas. Elas combinaram instrumentos tradicionais, como crédito e assistência técnica, com mecanismos inovadores, como apoio à comercialização (SCHNEIDER; ESCHER, 2014). Seus resultados contribuíram para recolocar a discussão sobre as políticas públicas para o meio rural e também reanimaram a discussão sobre o papel da denominada agricultura familiar nos processos de desenvolvimento rural.

Nesse debate, Alves e Rocha (2010) argumentam que está em curso um processo crescente de concentração da produção, de diferenciação entre produtores e de migração para as cidades de parte significativa da população rural. Esses autores defendem à necessidade de políticas públicas diferenciadas de acordo com o perfil de três grupos de agricultores, configurados de acordo com o valor da produção total. Um primeiro grupo, minoritário, seria responsável pela maior parte da produção e representaria o segmento viabilizado do setor. Além de um grupo intermediário, com chances de viabilização na agricultura, desde que apoiado com políticas públicas diferenciadas, haveria um terceiro grupo, majoritário numericamente, que não teria possibilidades de viabilização na agricultura e que, cedo ou tarde, migraria para as cidades. Nesses termos, a produção agropecuária familiar, incluída nesse terceiro grupo, teria pouca relevância e viabilidade.

Em outra perspectiva, Tonneau e Sabourin (2007) argumentam pela importância da agricultura familiar, sustentando que esse segmento tem substantivas contribuições ao desenvolvimento rural, tanto no sentido da inclusão social, do incremento produtivo e do combate à fome. Essa perspectiva é corroborada pela FAO (2015) em seu recente documento sobre o estado da alimentação e a agricultura no mundo. De acordo com Mattei (2014) a 
agricultura familiar apenas recentemente passou a receber apoio público específico, respondendo de forma imediata e positiva a esses estímulos, em termos econômicos, produtivos e sociais. Nesta perspectiva, a qual este trabalho se alinha, esse grupo social possuiria grande relevância, devido à sua contribuição para a segurança e a soberania alimentar, além da capacidade de respostas positivas às políticas públicas.

Por outro lado, a generalização dos impérios alimentares e da industrialização se colocam como ameaças as diversas formas da agricultura familiar. Vive-se sob a possibilidade de uma crise agrária, que teria como uma de suas características a insuficiência de alimentos, em termos quantitativos e qualitativos (PLOEG, 2008). É nesse cenário que a agricultura familiar ganha destaque, por sua contribuição na produção de alimentos e sua importância estratégica para a superação da pobreza (TONNEAU; SABOURIN, 2007).

A relevância da realização deste estudo está associada à crescente vinculação dos agricultores familiares aos mercados. Os processos e dinâmicas de reprodução social da agricultura familiar estão diretamente ligados ao conteúdo dessa relação, considerando que as maiores, ou menores, possibilidades dessa reprodução estarem associadas aos vínculos mercantis estabelecidos por estes sujeitos (GAZOLLA; PELEGRINI, 2011). A relação com os mercados coloca o tema da autonomia comercial dos agricultores, entendida como o controle, maior ou menor, que os agricultores possuem sobre os canais de comercialização, como elemento central na análise das estratégias de reprodução social e, em sentido mais amplo, para o estudo do desenvolvimento rural.

O objetivo do presente artigo é analisar as implicações que a inserção nos mercados institucionais, especificamente no Programa de Aquisição de Alimentos - PAA, gera nas dinâmicas de venda da produção e na autonomia comercial dos agricultores associados da Cooperativa Mista Agropecuária e Economia Solidária (COOPERSOL) e da Cooperativa dos Agricultores Porto Vera Cruz (COOPOVEC). A questão geral que orientou o estudo foi: a ampliação dos processos de mercantilização, via mercados institucionais, através do PAA, é capaz de se concretizar em uma estratégia efetiva de reforço da autonomia comercial dos agricultores familiares associados a essas duas cooperativas?

Mais especificamente, o presente trabalho analisa as implicações que a inserção nos mercados institucionais gera nas dinâmicas de uso dos demais canais de comercialização utilizados pelos agricultores. Com base no estudo de caso junto a COOPERSOL e a COOPOVEC procurou-se identificar em que medida o ingresso no PAA se associa com a ampliação, ou redução, nas taxas de uso dos demais canais de comercialização, buscando verificar se as mudanças transcorridas apontam para a ampliação, ou diminuição, da autonomia comercial dos agricultores.

Frente a esses objetivos, foram adotadas três hipóteses de trabalho. A primeira afirma que a inserção no PAA implica na ampliação dos processos de mercantilização dos associados da COOPERSOL e da COOPOVEC, entendida essa ampliação como o aumento no número total de canais de comercialização utilizados pelos agricultores. A segunda hipótese preconiza que o PAA concorre com os outros canais de comercialização dos agricultores produzindo mudanças em suas dinâmicas comerciais, gerando alterações significativas na magnitude de utilização dos diferentes canais previamente utilizados. A terceira hipótese afirma que, após ingresso no PAA, ocorrerá ampliação da autonomia comercial dos associados da COOPERSOL e da COOPOVEC, com aumento no uso de canais de comercialização onde os 
agricultores possuem maior poder e controle e diminuição no uso de canais onde os agricultores apresentam menor poder e controle.

A pesquisa combinou aspectos quantitativos e qualitativos. O caráter quantitativo é expresso pela mensuração e análise de diversas variáveis, obtidas de fontes primárias e secundárias. Ao longo do trabalho ganha relevo, sobretudo, a análise quantitativa das taxas de uso dos diversos canais de comercialização. Todavia, optou-se por não submeter essas variáveis a uma análise de caráter puramente estatístico, por entendermos que seria mais útil a elucidação das questões de estudo a contextualização e a historicização dos processos. Aí ganha relevo o caráter qualitativo da pesquisa, que engloba o mundo das relações humanas, o universo dos significados, das motivações e das atitudes dos sujeitos (MINAYO, 2012).

Os dados primários foram obtidos em estudo de caso junto às duas cooperativas citadas e foram gerados através de entrevistas em profundidade, com assessores técnicos das cooperativas e líderes dos agricultores. Além disso, foi realizada observação participante, com registro em diário de campo e consulta a banco de dados secundários. Também foram aplicados questionários estruturados junto a 20 agricultores da COOPOVEC que participavam do PAA, nos meses de outubro e novembro de 2014. Esse número representou $25 \%$ dos agricultores que integraram o projeto daquele ano e $20 \%$ do total de associados da cooperativa. Entre os agricultores da COOPERSOL foram aplicados questionários junto a 23 agricultores, em setembro e outubro de 2013 e nos mesmos meses de 2014. Esse número representou $25 \%$ dos agricultores que integraram o projeto daquele ano. O número de agricultores consultados foi determinado por amostragem aleatória por cotas (BARBETTA, 2011).

O presente artigo está organizado em outras seis seções, além dessa introdução e considerações finais. A segunda seção analisa o processo de mercantilização da agricultura e os mercados institucionais, destacando também a questão da agência dos agricultores. A terceira seção apresenta alguns traços da agricultura regional e da trajetória das cooperativas estudadas. $\mathrm{Na}$ quarta seção se discute o tema da autonomia comercial dos agricultores e se apresenta a proposta de sua operacionalização no âmbito da pesquisa realizada. Na quinta seção são apresentados os dados do estudo, em que se analisa a variação no uso de outros canais de comercialização após os agricultores ingressarem no PAA. Na penúltima seção são apresentados os resultados da pesquisa em relação à variação da autonomia comercial dos agricultores e, por fim, apresentam-se algumas considerações a título de conclusão.

\section{MERCANTILIZAÇÃO, MERCADOS INSTITUCIONAIS E AGRICULTURA FAMILIAR}

O ponto de partida da presente análise é a consideração de que toda ação econômica é socialmente situada e as instituições econômicas são construções sociais (GAZOLLA; PELEGRINI, 2011). Para Granovetter (2003) é um equívoco conceituar as ações econômicas sem enraizá-las em redes de relações interpessoais, ou de forma a torná-las independentes. Por isso, é fundamental analisar os fatos econômicos em suas vinculações com os fatos sociais e, para tal, o autor apresenta o conceito de enraizamento. Segundo Grisa (2010), com esse 
conceito procura-se analisar teoricamente como a ação econômica está enraizada em relações sociais e se afirma que os mercados devam ser estudados como estruturas sociais.

Para Marsden et al. (1995, p. 293) "A mercantilização não representa um processo único e universal [...]". A mercantilização deve ser compreendida como um amplo processo social. Ela não fica restrita ao trabalho na agricultura, mas alcança as práticas sociais dos agricultores e resulta em dinâmicas diferenciadas de desenvolvimento do capitalismo no espaço agrário e em dinâmicas desiguais de desenvolvimento rural. Para compreender o desenvolvimento histórico da agricultura familiar é preciso considerar que ela está inserida em uma economia de mercado (CONTERATO, 2004).

Concebe-se a agricultura familiar contemporânea, de acordo com Conterato (2008, p. 68), "[...] como uma forma social de trabalho e produção que se reproduz em um ambiente amplamente mercantilizado". Portanto, para compreender adequadamente as dinâmicas de desenvolvimento rural e os processos de transformação é fundamental estudar o modo como os agricultores se inserem, constroem e se relacionam com os mercados.

Compreende-se a mercantilização como um processo, onde a reprodução da agricultura familiar torna-se mais dependente de suas relações com o mercado e, segundo Conterato (2004, p. 34) "A produção e a circulação de mercadorias orientam estas relações, quebrando o isolamento desta produção familiar, passando a vincular-se com o mercado num processo gradual e contínuo".

Assim, a mercantilização se internaliza nas unidades de produção e nas dinâmicas familiares através da crescente aquisição de insumos externos utilizados diretamente nos processos de produção, compondo o que Ploeg (2009) denominou de externalização. Por outro lado, ela também se desenvolve e internaliza pela destinação dada aos diversos objetos produzidos nas atividades agropecuárias, que assumem características de mercadorias, ao serem destinados não para o consumo familiar, ou das atividades produtivas, mas para a venda.

Segundo Conterato (2004, p. 34), "Ao ingressar no sistema mercantil de produção e circulação de mercadorias, a forma familiar de produção passa a ser influenciada pelas relações que orientam estas práticas." Nessa perspectiva Niederle (2007) argumenta que, nos últimos trinta ou quarenta anos, ocorreu a dinamização do processo de mercantilização da agricultura familiar, o que gerou mudanças significativas em suas atividades produtivas e também nas dinâmicas sociais. Todavia, os agricultores não são sujeitos passivos ou inertes, sob os quais, forças estruturais externas agem e determinam unilateralmente sua conformação. Ao contrário disso, como argumenta Long (2007), eles são ativos processadores de informações e desenvolvedores de estratégias que se estabelecem nas relações mantidas com outros atores e com instituições.

A condição social de ator é alcançada à medida que se estabelecem interações sociais, construindo agência, ao agir, ou reagir, em contextos adversos e situações hostis, através da mobilização de recursos, capacidades e desenvolvimento de estratégias que possibilitem "fazer diferente" (SCHNEIDER; GAZOLLA, 2011). As diferentes configurações de organização social emergem e resultam das interações, negociações e lutas sociais entre os diferentes atores, incluindo as lutas imediatas e presentes, bem como aquelas mais distantes e 
não presenciais. Todas elas influenciam a configuração da organização social, afetando as ações e os resultados (PLOEG; LONG, 1994).

Neste sentido, os agricultores agem constituindo diferentes estratégias e também estilos de agricultura. Os estilos de agricultura envolvem variações em torno de um conjunto de noções estratégicas e valores que os agricultores usam como guias, das formas como estruturam as práticas produtivas e também das relações estabelecidas entre a unidade de produção e os mercados. Os diferentes estilos de agricultura são constituídos na imbricação das estruturas sociais, econômicas e culturais (NIEDERLE et al., 2014).

Isso possibilita à agricultura familiar uma grande capacidade de adaptação aos diversos contextos históricos. Segundo Wanderley (2009), a heterogeneidade das formas sociais concretas da agricultura familiar resulta, mais do que das diferenças de renda auferidas, da diferenciação de estratégias multifacetárias adotadas por esses sujeitos, frente às diversas situações econômicas, sociais, ambientais e culturais. Portanto, a mercantilização não conduz necessariamente a um único padrão de relação dos agricultores familiares com os mercados, pois os mesmos podem adotar diferentes estratégias de relação comercial.

Concorda-se com Conterato et al. (2011) para quem os mercados não são estruturas rígidas e externas, mas espaços sociais resultantes da interação de diversos atores, entre eles os agricultores familiares que tomam parte ativa nesse jogo. O processo de mercantilização implica negociação e disputas, tanto materiais como simbólicas, para o controle dos mercados, compondo processos heterogêneos, complexos e não lineares. Portanto, os mercados são construções sociais e históricas em que, conforme Conterato et al. (2011, p. 71), "[...] atores (individuais e coletivos) disputam recursos e colocam em interface diferentes valores, normas e interesses".

O Estado é um dos agentes fundamentais que atuam, mais ou menos ativamente, no processo de configuração dos mercados. Segundo Schneider (2010) e Grisa (2012), para a agricultura familiar, desde meados dos anos 1990, o Estado brasileiro tem-se colocado nos espaços rurais de forma mais intensa, incidindo mais ativamente na configuração do rural contemporâneo.

As políticas públicas, como as de acesso preferencial a determinados mercados, podem cumprir papel fundamental nas estratégias de reprodução e busca de autonomia dos agricultores. Uma das expressões dessa ação estatal é a constituição de mercados institucionais, notadamente o PAA, ou a reconfiguração do Programa Nacional de Alimentação Escolar - PNAE, em 2009, que têm o Estado como agente de sustentação.

De forma mais precisa, segundo Grisa (2010, p. 103), designa-se mercado institucional como sendo uma conformação específica de mercado "[...] em que as redes de troca assumem uma estrutura particular, previamente determinada por normas e convenções negociadas por um conjunto de atores e organizações, onde o Estado geralmente assume um papel central, notadamente através de compras públicas". O programa constitui uma importante novidade nas políticas públicas, por articular o apoio à comercialização da produção da agricultura familiar com ações de segurança alimentar e nutricional (MENEZES et al., 2015).

Os mercados institucionais são uma modalidade específica de relação de troca onde o Estado, no caso específico do PAA, realiza a intermediação e o financiamento das operações de compra de alimentos dos agricultores familiares e a distribuição desses alimentos aos 
consumidores em situação de insegurança alimentar. Configuram-se como canais de comercialização que podem ser adicionados às diferentes estratégias comerciais desenvolvidas pelos agricultores, contando para tal com a mediação do Estado.

Ao observamos a produção bibliográfica recente sobre o PAA, destaca-se sua contribuição na geração de renda para os agricultores, ampliação da diversificação dos cultivos, acesso facilitado a novos canais de comercialização, estímulo a processos associativos, entre outras. Por outro lado, alguns estudos também apontam a insatisfação em relação ao tempo dos pagamentos, insegurança sobre a continuidade do programa, aos limites da cobertura e também críticas sobre o perfil dos agricultores beneficiados (GRISA et al., 2009; FREITAS, 2011; HOLANDA, 2012; SALGADO; DIAS, 2013; MARINHO, 2014; OLIVEIRA; BERGAMASCO, 2014; CORADIN; SOUZA, 2015; CIRINO et al., 2016).

Em seu conjunto, os estudos apontam positivamente para a contribuição do PAA aos agricultores familiares e, em termos globais, ao desenvolvimento rural. Os mercados institucionais se colocam como mais uma alternativa de reprodução social aos agricultores familiares (CORADIN; SOUZA, 2015) e, da mesma forma que Costa et al. (2015) observam ao estudar 19 cooperativas em Minas Gerais, essa modalidade de mercado representava o mecanismo mais importante de comercialização de duas cooperativas estudadas. Todavia, considerando o universo dos agricultores familiares dos municípios estudados, a participação nesses mercados ainda é relativamente pequena, da mesma forma que apontam SouzaEsquerdo e Bergamasco (2014) ao analisar a participação nas políticas públicas dos agricultores familiares do "Circuito das Frutas" em São Paulo.

As insuficiências da cobertura do PAA também são apontadas por Salgado et al. (2015), mas é fundamental destacar que os mercados institucionais foram constituídos para enfrentar o estrangulamento dos pequenos agricultores nos processos comerciais, se apresentando como alternativa ao mercado de commodities. Isso coloca a importância de avaliar a inserção dos agricultores nesses mercados, para se verificar em que medida eles se associam às estratégias de comercialização de caráter mais empresarial - onde o capital possui maior poder e controle sobre os canais de venda e os agricultores, em termos gerais, menor poder e capacidade de controle, ou a estratégias comerciais que geram maior autonomia aos agricultores. Vejamos na seção que segue alguns traços da trajetória da agricultura regional, da história e vinculação das cooperativas pesquisadas com os mercados institucionais para, desde aí, ponderar as conexões do programa com a autonomia dos agricultores.

\section{AGRICULTURA REGIONAL E A GÊNESE DA COOPOVEC E DA COOPERSOL}

A COOPERSOL e a COOPOVEC atuam na Região Fronteira Noroeste do Rio Grande do Sul, sendo sua base composta, principalmente, por agricultores dos municípios de Santa Rosa, Tuparendi, Santo Cristo e Porto Vera Cruz. Os tipos de agricultores existentes na região, em termos gerais, podem ser divididos em três grandes grupos. O primeiro, composto por agricultores familiares que desenvolvem suas atividades em pequenas propriedades, com uso predominante de mão de obra familiar, com intensa inserção mercantil e internalização da modernização. O segundo tipo de agricultores possui traços mais camponeses, usa mão de obra familiar, com menores graus de inserção mercantil e com incorporação parcial do 
processo de modernização. O terceiro tipo desenvolve uma agricultura de caráter patronal, que é desenvolvida em médias e grandes propriedades, usa mão de obra familiar e contratada, possui caráter mais empresarial, estando integralmente pautada pelos processos da modernização. O universo de pesquisa é composto por agricultores que, em termos gerais, compõem os dois primeiros tipos mencionados e ao longo desse trabalho serão denominados de agricultores familiares.

Os padrões sociais e produtivos da agricultura regional foram fortemente marcados pela chegada de colonizadores, nas primeiras décadas do século XX e pelo processo de modernização da agricultura, sobretudo a partir dos anos 1950. Atualmente trata-se de uma agricultura mercantilizada, com elevados níveis de externalização e integrada aos circuitos globais de produção, sobretudo nas atividades produtivas especializadas, como a produção de soja, milho, trigo, fumo, suínos, leite e, em menor escala, de aves. Os sujeitos pesquisados desenvolvem uma agricultura de base familiar bastante diversificada, em muitos espaços de forma paralela a essa agricultura especializada e em outros espaços, de forma combinada a ela.

Na segunda metade do século XX a região passou pelo processo de modernização da agricultura. Também denominado de "Revolução Verde", esse processo foi fortemente impulsionado pelo Estado brasileiro. Conforme Mazoyer e Roudart (2010), na esteira de mudanças que também ocorriam em nível internacional, foram criados modernos centros de pesquisa para selecionar e melhorar espécies animais e vegetais com maior capacidade de resposta produtiva a insumos industriais. Buscou-se a padronização e homogeneização dos cultivos, para permitir a máxima mecanização das atividades agropecuárias, embora isso estreitasse significativamente a base genética das espécies e ampliasse a vulnerabilidade das mesmas ao ataque de "pragas agrícolas" e doenças. Para fazer frente a esses problemas, foram desenvolvidos modernos "defensivos" e, para a correção da fertilidade dos solos, adubos de síntese industrial. Esse conjunto de tecnologias, associadas e interligadas, englobando sementes, adubos, agrotóxicos e máquinas, denominou-se de pacote tecnológico, sendo ele produzido e controlado pelas indústrias. Conforme Graziano da Silva (1996) tudo isso possibilitou o avanço capitalista no campo, tornando a agricultura mais dependente da indústria e do capital financeiro.

O processo de formação da agricultura regional, em termos ecológicos, se assentou sobre os Biomas Pampa e Mata Atlântica, que tem na região uma zona de transição. Os agricultores consultados nos municípios de Santa Rosa e Tuparendi possuem suas terras em áreas com maiores vínculos com o Bioma Pampa, que facilitou, em termos ambientais, o processo de incorporação da modernização da agricultura. Já os agricultores de Porto Vera Cruz possuem suas áreas mais vinculadas ao Bioma Mata Atlântica, que apresenta limites ecológicos a internalização da modernização da agricultura nos sistemas produtivos.

Os sistemas produtivos baseados na revolução verde são criticáveis por sua fragilidade em termos de sustentabilidade, devido à dependência de insumos externos e de recursos não renováveis. Para Caporal (2009), apesar da modernização da agricultura ter impulsionado o aumento da produção e da produtividade, também gerou sérios problemas ambientais e sociais, como a redução da biodiversidade, erosão dos solos, assoreamento dos rios, estreitamento da base genética, envenenamento alimentar, exclusão social, concentração de terras, etc. Os efeitos negativos da revolução verde tornam-se mais evidentes nas décadas 
finais do final do século XX, dado o processo de erosão e empobrecimento dos solos, o grau de empobrecimento e endividamento dos agricultores, além do êxodo rural bastante intenso.

O processo de constituição das duas cooperativas evidencia a agência dos agricultores (LONG, 2007), demonstrando sua capacidade de reação frente a esse contexto de privações em que estavam inseridos (PLOEG, 2008). A criação das cooperativas expressa sua intencionalidade de incidir sobre essa realidade, que lhes era adversa, aspirando por mudanças que lhes fossem favoráveis.

Assim, no ano de 2004 foi criada a COOPOVEC. Essa cooperativa tem sua base social constituída por agricultores familiares do município de Porto Vera Cruz - RS. Esse município localiza-se na região Fronteira Noroeste, tendo uma população de 1566 habitantes e área de $113,6 \mathrm{~km}^{2}$. O município localiza-se na fronteira com a República Argentina, estando a cerca de $550 \mathrm{~km}$ da capital gaúcha, Porto Alegre.

A criação dessa cooperativa foi impulsionada pelo desejo dos agricultores de encontrar alternativas produtivas e de comercialização ao cultivo do tabaco, que na época era a principal atividade produtiva da maioria dos 20 sócios fundadores. Com a criação da cooperativa esses sujeitos procuravam, através da associação, constituir uma ferramenta que lhes permitisse implantar alternativas produtivas ao tabaco e, principalmente, que viabilizasse os processos de comercialização. Organizados em cooperativa os agricultores pretendiam ampliar sua capacidade de agência, para a construção de projetos alternativos de desenvolvimento, com maior enraizamento local, melhores possibilidades de protagonismo dos agricultores e independência das empresas de tabaco.

Para a criação da COOPOVEC os agricultores contaram com apoio da Cooperativa de Eletrificação Rural Fronteira Noroeste LTDA (COOPERLUZ), da EMATER, da Secretaria Municipal de Agricultura e da Associação Regional de Desenvolvimento (AREDE). Nos primeiros anos foram desenvolvidas experiências de produção de frutas e hortaliças, mas o maior limite para a viabilização dessas atividades era a comercialização da produção. No caso da produção de tabaco, a venda era contratualmente garantida pelas empresas integradoras, $o$ que colocava os agricultores numa posição de certa passividade e com limitadas possibilidades de acúmulo de conhecimentos nos processos de venda.

No ano de 2006, quando se iniciam as experiências da cooperativa com o PAA, a dinâmica de funcionamento da COOPOVEC se altera significativamente. Esse programa desempenhou um papel profundamente transformador no funcionamento da cooperativa e na vida dos associados, pois ele constituiu como a primeira alternativa que, efetivamente, garantia a comercialização da produção local alternativa ao tabaco.

Além da negociação prévia do preço a ser pago pelos produtos dos agricultores, a garantia de venda segue sendo apontada pela direção da cooperativa como elemento fundamental para a atual adesão dos agricultores ao programa. Os primeiros projetos tinham duração inferior a um ano e os valores totais foram, gradativamente, aumentando ao longo dos anos. Do primeiro projeto, no valor de $\mathrm{R} \$ 17.000,00 \mathrm{em} 2006$, passou-se a um projeto de $\mathrm{R} \$$ 340.000,00 em 2014-2015, envolvendo, nesse último, 64 associados.

Todos os projetos de PAA executados pela COOPOVEC foram através da Modalidade Compra com Doação Simultânea. No projeto 2013 - 2014 os alimentos eram enviados para a cidade de Santa Rosa, onde eram entregues 758 cestas e para a cidade de Porto Lucena, onde 
se entregavam 121 cestas, totalizando 879 cestas mensais. Essas sacolas de alimentos estavam compostas por grande diversidade de alimentos, envolvendo 37 diferentes produtos, sobretudo frutas e hortaliças.

Já a COOPERSOL foi fundada no ano de 2006, por agricultores familiares de Santa Rosa - RS, mas com pretensão de atuação em toda a região noroeste do RS. Tem sua sede nesse município, contando, em 2014, com 149 associados. A área de trabalho é, sobretudo, nos municípios de Santa Rosa e Tuparendi, mas também abrange, secundariamente, agricultores de Santo Cristo, Tucunduva, Giruá, Porto Mauá e Alecrim. Essa dispersão geográfica dos associados apresenta-se como um desafio ao funcionamento da cooperativa. Diferente da COOPOVEC, a pesquisa evidenciou que, no caso da COOPERSOL, as ações têm sido insuficientes para constituir uma dinâmica integradora e de efetiva cooperação entre os associados.

Os motivos que levaram a criação da COOPERSOL também estão relacionados às dificuldades que os agricultores enfrentavam nos processos de comercialização. O objetivo da cooperativa é servir como instrumento de apoio ao fortalecimento e desenvolvimento de estratégias e canais de comercialização mais favoráveis aos agricultores associados. Um dos eixos estruturantes da atuação da cooperativa é a economia solidária.

A COOPERSOL iniciou os trabalhos com o PAA no ano de 2011, envolvendo cerca de 90 famílias associadas. Desses agricultores, 39 residiam no município de Santa Rosa, 39 em Tuparendi, três em Tucunduva, cinco em Santo Cristo e quatro em Porto Mauá. Essa foi a primeira experiência da COOPERSOL com esse canal de comercialização e também foi com a Modalidade Compra com Doação Simultânea. Nessa época, foram comercializados 22 produtos, sobretudo hortifrutigranjeiros, mas também derivados lácteos e carne, compondo cestas entregues mensalmente para 285 famílias - sendo 220 em Santa Rosa e 65 em Tuparendi. O segundo projeto (2013 - 2014) envolveu 109 famílias de agricultores e promoveu a entrega de 789 cestas de alimentos.

A garantia de compra e a definição prévia dos preços são destacados, pelos dirigentes da cooperativa, como os grandes diferenciais favoráveis do PAA. É importante assinalar que, diferente dos associados da COOPOVEC, boa parte dos associados da COOPERSOL já possuía experiência individual com a comercialização de hortifrutigranjeiros em outros canais, como feira de produtores, entrega na casa de consumidores, entrega em fruteiras, padarias, etc. na cidade de Santa Rosa. Além disso, também possuíam longa experiência com a comercialização de grãos, sobretudo soja, milho e trigo. Assim, no caso da COOPERSOL, o PAA apresentava-se aos agricultores como um canal de comercialização a mais, que poderia ser utilizado pelos associados da cooperativa.

Nesse contexto, se insere o presente trabalho, que tem por objetivo verificar como os mercados institucionais, especificamente o PAA, no caso das duas cooperativas estudadas, se combinam com os demais canais de comercialização utilizados pelos agricultores, analisando as modificações geradas nas dinâmicas comerciais e se as mesmas apontam para a ampliação, ou redução, da sua autonomia comercial. Isso coloca a questão de como definir e, sobretudo, como operacionalizar as variações na autonomia comercial dos agricultores. Essas são as questões enfrentadas na seção que segue. 


\section{AUTONOMIA COMERCIAL: UMA PROPOSTA DE OPERACIONALIZAÇÃO}

Como vimos, as diferentes trajetórias de inserção mercantil contribuem para a constituição de um quadro heterogêneo, gerando diversos estilos de agricultura. Para Ploeg e Long (1994), essa diversidade de estilos de agricultura pode ser analisada observando-se o grau de autonomia, ou dependência, diante do mercado global e do fornecimento de tecnologia.

Os graus de mercantilização resultam, conforme Schneider e Nunes (2013, p. 608), “[...] do afastamento ou aproximação da dependência por parte dos atores do mercado, cuja escolha pelo consumo de mais ou menos elementos externos ou internos produz movimentos que os afastam ou os aproximam de certos mercados nocivos a eles, como monopólios, oligopólios, etc.” Esses autores argumentam que isso não significa que os agricultores não devam se relacionar com os mercados. Sustentam que eles devem desenvolver estratégias que os capacitem para colocá-los numa posição de maior liberdade e autonomia, quando estabelecerem essas relações.

Discutindo as implicações da maior ou menor inserção mercantil dos agricultores familiares nos processos de diferenciação social e ampliação, ou redução, de sua autonomia Conterato et al. (2011, p.75) argumentam que "Mercados podem se constituir em mecanismos de inserção social e econômica e resultar no fortalecimento da autonomia frente às vulnerabilidades enfrentadas, quaisquer que sejam suas origens". Concorda-se com esta perspectiva de que, não necessariamente, a ampliação da inserção mercantil dos agricultores familiares represente algo indesejável, ou nefasto para sua condição de produtor, para sua qualidade de vida e para sua reprodução social.

A luta por autonomia é uma das características fundamentais da agricultura camponesa (PLOEG, 2008) e o maior domínio sobre os processos de comercialização da sua produção, através do controle dos canais de venda, corresponde ao que se denomina, neste trabalho, de autonomia comercial dos agricultores. Entende-se que a forma de comercialização da produção é uma das múltiplas faces que compõem um complexo quadro de variáveis que configura os diferentes estilos de agricultura, que podem ser mais, ou menos autônomos. Isso coloca a necessidade do estabelecimento de parâmetros para auferir variações na autonomia comercial dos agricultores.

Cabe ressaltar que não está se considerando que a autonomia dos agricultores possa ser determinada ponderando apenas suas práticas de comércio. Considera-se o caráter dos vínculos mercantis, nos processos de venda da produção, como uma das dimensões a ser considerada, em um conjunto mais amplo de fatores e variáveis que devem ser avaliados para se verificar a condição de maior, ou menor autonomia dos agricultores. $\mathrm{O}$ foco nos aspectos comerciais, proposto nesse estudo, está associado à necessidade de recortes de pesquisa para operacionalização da autonomia.

Logo, a autonomia dos agricultores não pode ser tributária de apenas uma variável. Nesse estudo ater-se-á a apenas a uma dessas dimensões, que é o maior ou menor controle que os agricultores possuem sobre os mecanismos de comercialização de sua produção. Para a operacionalização do estudo propõe-se, como indicador da variação na autonomia comercial, a mensuração das taxas de uso, pelos agricultores, dos diferentes tipos de canais de 
comercialização, segundo classificação apresentada na sequência. Os canais de comercialização, de acordo com Waquil et al. (2010), são definidos como um conjunto sequencial de etapas, entre produtores e consumidores, por onde passam os produtos agrícolas, integrado por intermediários e um arranjo institucional que viabiliza as trocas nas cadeias produtivas.

Os canais de comercialização podem ser diretos ou indiretos, dependendo da existência, ou não, de intermediários entre os produtores rurais e os consumidores no processo de comercialização. Além disso, caso existam intermediários, os canais são classificados segundo o número destes ao longo do processo de intermediação entre os produtores e os consumidores (WAQUIL et al., 2010).

No caso de um produtor que vende diretamente ao consumidor final, tem-se um canal de nível zero (N0), pois inexistem intermediários. Isso ocorre no caso de feiras, ou da venda direta que os produtores fazem na casa dos consumidores. Os canais de nível um (N1) são aqueles que possuem um intermediário no processo de comercialização dos produtos agropecuários. É o caso dos supermercados e fruteiras que compram as mercadorias diretamente dos produtores e os revendem para os consumidores. Os canais de dois níveis são aqueles que possuem dois intermediários (WAQUIL et al., 2010, p. 59 adaptado de KOTLER, 1998). Assim, o nível dos canais vai variando de acordo com a variação do número de intermediários que se colocam entre produtores e consumidores.

Para efeitos de operacionalização desse estudo considerar-se-á três grupos de canais de comercialização, sendo $\mathrm{N} 0, \mathrm{~N} 1$ (descritos no parágrafo anterior) e $\mathrm{N} \geq 2$. Os canais que possuem dois ou mais intermediários no processo de comercialização comporão apenas um grupo, denominado "nível dois, ou mais" $(\mathrm{N} \geq 2)$. No caso das cooperativas estudadas são exemplos desse grupo: as vendas que os agricultores fazem para as "agroindústrias", notadamente de leite, grãos e fumo.

Em termos mais qualitativos, entende-se que os canais de nível zero possuem maiores possibilidades de controle dos agricultores, pois o processo de venda ocorre em nível mais local e está sob maior domínio desses sujeitos. À medida que se avança para os canais com maior número de intermediários, esse controle do agricultor tende a ir diminuindo. Segundo Gazolla e Pelegrini (2011), os canais mais curtos são interessantes por serem os próprios agricultores os vendedores de seus produtos, constituindo um vínculo direto entre os produtores e os consumidores, num contexto de relações sociais locais e enraizadas. Além disso, nesses canais não são necessários os atravessadores e intermediários, o que possibilita, tendencialmente, que os agricultores aufiram melhores rendimentos e, de acordo com Rotoli e Scalco (2016), tornem seu negócio mais eficiente.

Em termos operacionais, argumenta-se que os canais N0 são aqueles em que os agricultores possuem maior poder e controle no processo de comercialização da sua produção, por isso considerar-se-á com autonomia alta. À medida que se avança para $\mathrm{N} 1$ e $\mathrm{N} \geq 2$ esse poder e controle dos agricultores vai diminuindo, por isso considerar-se-á que sua autonomia passa para média e baixa, respectivamente. No Quadro 1 apresentamos a classificação dos canais de comercialização encontrados no estudo, de acordo com o número de intermediários e a correlação estabelecida com a autonomia dos agricultores. 
Quadro 1 - Classificação dos canais de comercialização por nível e vinculação com diferentes graus de autonomia comercial dos agricultores.

\begin{tabular}{|l|l|c|}
\hline NÍVEL & \multicolumn{1}{|c|}{ CANAIS DE VENDA } & $\begin{array}{c}\text { AUTONOMIA COMERCIAL DOS } \\
\text { AGRICULTORES }\end{array}$ \\
\hline N0 & $\begin{array}{l}\text { Feiras; Entrega na casa de consumidores; Entrega na casa } \\
\text { de vizinhos; Venda para consumidores na propriedade; } \\
\text { Venda para hospitais. }\end{array}$ & ALTA \\
\hline N1 & $\begin{array}{l}\text { Para atravessadores na propriedade; Mercado da } \\
\text { UNICOOPER - COOPERSOL; Outros supermercados; } \\
\text { PNAE; Eventos ou festas; PAA. }\end{array}$ & MÉDIA \\
\hline $\mathrm{N} \geq 2$ & Para agroindústrias; Integração com empresas. & BAIXA \\
\hline
\end{tabular}

Fonte: Dados da pesquisa, 2013 e 2014.

Argumenta-se, neste estudo, que essa tipificação dos canais, segundo os diferentes níveis, possibilitará a verificação das variações nas taxas de uso dos diferentes níveis dos canais de comercialização ( $\mathrm{N} 0, \mathrm{~N} 1$ e $\mathrm{N} \geq 2$ ), antes e depois do ingresso dos agricultores no PAA. Isso permitirá observar se a intensidade no uso desses diferentes canais se associa positivamente, ou negativamente, com o ingresso no PAA. Assim, se poderá verificar a relação entre o ingresso no PAA e o aumento ou diminuição da autonomia comercial dos agricultores.

\section{O PAA E MUDANÇAS NO USO DE OUTROS CANAIS}

A comparação entre o número total de canais de comercialização utilizados antes e após a participação no PAA, sendo esse incluído nessa contagem, permitiu verificar o número de casos em que houve aumento ${ }^{3}$, manutenção ${ }^{4}$ ou diminuição nesse número. No Gráfico 1 estão os dados relativos aos agricultores das duas cooperativas estudadas.

Segundo Grisa et al. (2009) o ingresso no PAA tem contribuído para o fortalecimento ou criação de novos mercados para os agricultores familiares, possibilitando o aumento do número de canais de comercialização utilizados. Essa mesma tendência, conforme o Gráfico 1, pode ser observada no caso da COOPERSOL, em que ocorreu aumento no número total de canais utilizados para a maioria dos agricultores (65\%). Por outro lado, para um grupo menor de agricultores $(13 \%)$ dessa cooperativa ocorreu diminuição no número total de canais utilizados.

No caso da COOPOVEC, observa-se que houve aumento no número de canais de comercialização utilizados para cerca de metade dos agricultores, após o ingresso no PAA. Por outro lado, observa-se que para cerca de um terço dos agricultores (35\%) dessa cooperativa ocorreu diminuição nesse número. Ao juntarem-se os casos em que se observou diminuição $(35 \%)$ com manutenção $(20 \%)$ do número total de canais utilizados, tem-se que,

\footnotetext{
${ }^{3}$ Quando o número total de canais utilizados pelo agricultor, após o ingresso no PAA, for superior ao número total de canais utilizados antes do ingresso no PAA.

${ }^{4}$ Quando o número total de canais utilizados pelo agricultor, antes e após o ingresso no PAA, for igual. Para isso ocorrer, o agricultor terá que, necessariamente, interromper o uso de um canal após o ingresso no PAA. Se interromper o uso de dois ou mais canais, ocorrerá diminuição no número total de canais utilizados.
} 
para cerca de metade dos agricultores dessa cooperativa, o ingresso no PAA não se associou com o aumento do número total de canais utilizados. Ou seja, no caso da COOPOVEC, o ingresso no PAA se associa com o aumento no número de canais de comercialização utilizados para metade dos agricultores e para outra metade isso não se observa.

Gráfico 1 - Tipo de variação no número total de canais de comercialização utilizados pelos agricultores da COOPERSOL e da COOPOVEC após a entrada no PAA - 2013 e 2014.

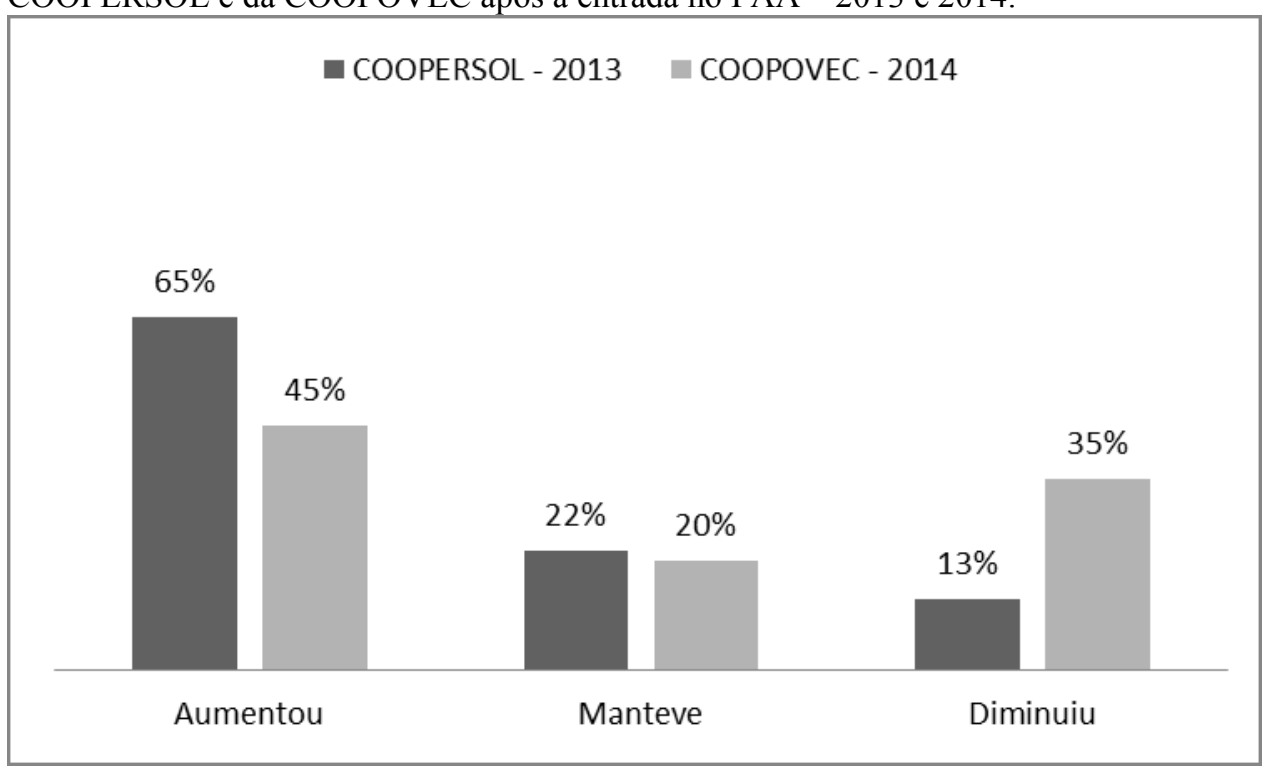

Fonte: Dados da pesquisa, 2013 e 2014.

No Gráfico 2 apresentam-se as informações comparativas da variação na taxa relativa de uso de diversos canais, antes e após a entrada no PAA. Essa variável expressa o tipo de mudança, se positiva, ou negativa, e a magnitude da mudança na taxa de uso de cada canal de comercialização após o ingresso dos agricultores no PAA. 
Gráfico 2 - Taxa de variação no uso dos canais de comercialização antes e após o ingresso no PAA COOPERSOL 2013 e COOPOVEC $2014^{5}$.

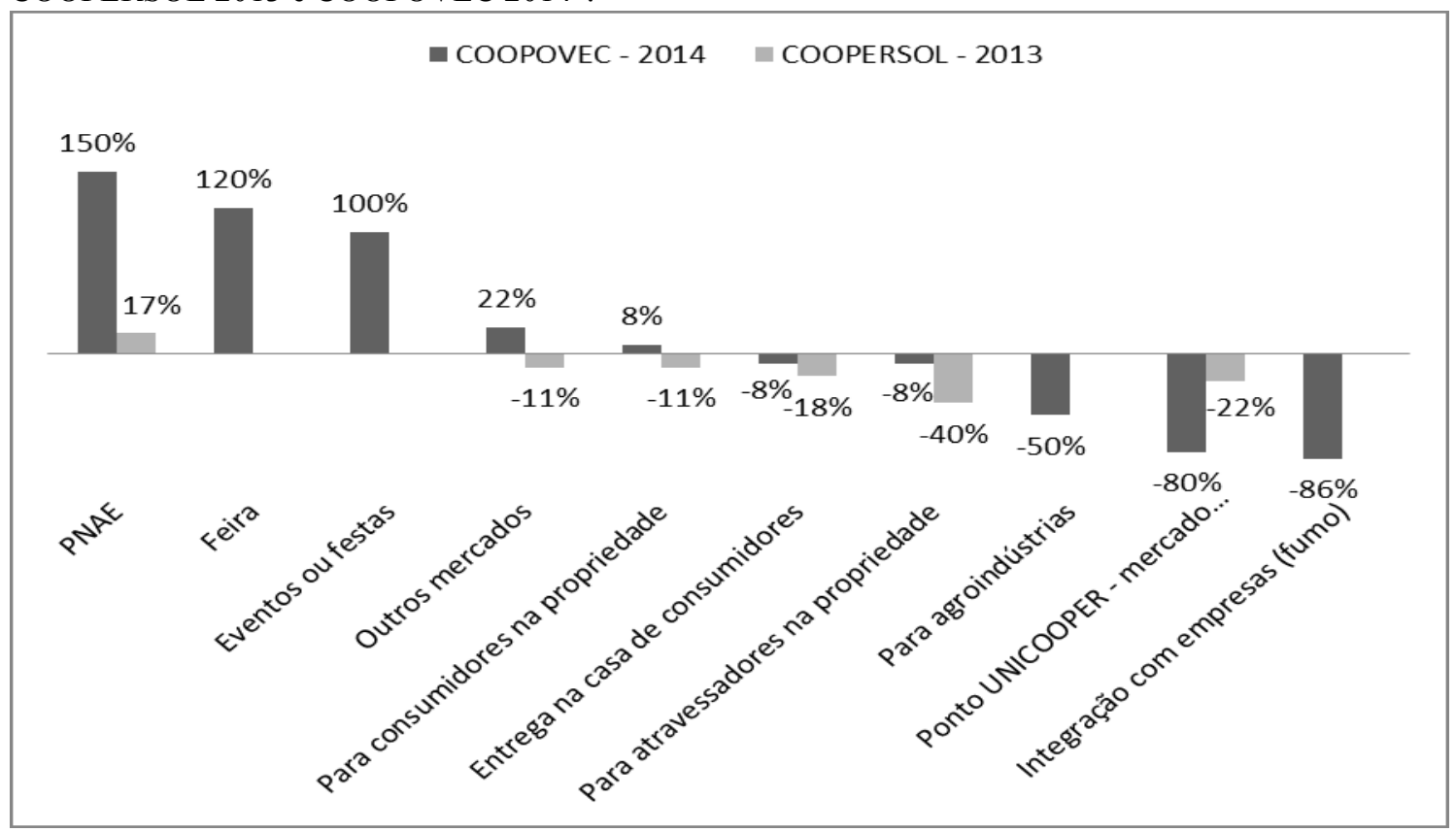

Fonte: Dados da pesquisa, 2013 e 2014.

As taxas de crescimento positivas e mais expressivas foram observadas nos canais PNAE, feira e eventos ou festas, todas entre os associados da COOPOVEC. Portanto, para esses três canais, no caso da COOPOVEC, tem-se uma associação positiva entre a entrada no PAA e o crescimento relativo bastante significativo no uso desses canais.

O PNAE é o único canal em que se observou variação positiva nas duas cooperativas estudadas. Portanto, o uso desse canal de comercialização se associa sinergicamente com o ingresso no PAA, ainda que em níveis bem distintos, entre as duas cooperativas.

Já em relação à venda em outros supermercados e para consumidores na propriedade também se observam taxas de crescimento positivas entre os associados da COOPOVEC. Todavia, para esses mesmos canais, no caso da COOPERSOL, observam-se taxas de crescimento negativas. Portanto, para esses dois canais, o ingresso no PAA se associa de forma diferente nas cooperativas estudadas, observando-se aumento em um caso e diminuição no outro.

Para as entregas nas casas dos consumidores e vendas para atravessadores na propriedade, no caso da COOPOVEC, observa-se redução de $8 \%$ em ambos. No caso da COOPERSOL, o primeiro canal teve redução de $18 \%$ e o segundo, de forma mais significativa, teve redução de $40 \%$. Portanto, o ingresso no PAA, ainda que com taxas distintas, se associa negativamente ao uso desses dois canais nas duas cooperativas estudadas.

No caso dos canais entrega para agroindústrias (leite ou grãos - milho, soja, trigo) e a venda para empresas integradoras, notadamente de fumo, no caso específico da COOPOVEC,

\footnotetext{
${ }^{5}$ No caso das entregas de produtos feitas em hospitais (realizada por $4 \%$ dos agricultores da COOPERSOL, tanto antes como depois do ingresso no PAA) e da venda para vizinhos rurais (feita por 10\% dos agricultores da COOPOVEC, tanto antes como depois do ingresso no PAA) não ocorreram alterações nas taxas de uso. Para maior clareza na apreciação dos demais dados esses não foram incluídos no Gráfico 2.
} 
têm-se taxas de redução bastante expressivas. No caso da venda para agroindústrias, que era realizada por $80 \%$ dos agricultores, antes do PAA, ocorre uma redução na ordem de $50 \%$, após o ingresso no programa. No caso da venda para empresas integradoras, que era usado por $75 \%$ dos agricultores antes do PAA, ocorre redução de $86 \%$, após o ingresso nesse programa. Isso significa que eram dois canais usados pela maioria dos agricultores associados da COOPOVEC, que tiveram sensível redução em seu uso, após o ingresso dos agricultores no PAA, revelando, nesse caso, uma associação negativa.

Nenhum dos associados da COOPERSOL utilizava o canal integração com empresas, tanto antes como depois do ingresso no PAA. Além disso, no caso da venda para agroindústrias, não ocorreu variação no nível de uso desse canal após o ingresso dos agricultores no programa.

Por fim, em relação ao canal ponto de venda da UNICOOPER - mercado da COOPERSOL, observa-se que, após o ingresso dos agricultores no PAA, ocorreu variação negativa em seu uso entre os associados das duas cooperativas, sendo a redução mais expressiva no caso da COOPOVEC.

\section{PARTICIPAÇÃO NO PAA E AUTONOMIA COMERCIAL}

Na Tabela 1 considera-se o número total de ocorrências dos diversos canais de comercialização entre os associados da COOPERSOL. Esse número representa o somatório de todas as observações de uso pelos agricultores dos diversos canais que compõem cada nível, antes e depois do ingresso no PAA.

No caso dos associados da COOPERSOL, conforme se observa na Tabela 1, o ingresso no PAA se associa com alterações negativas, embora não muito expressivas (-9\%), na taxa de uso dos canais $\mathrm{N} 0$ e não se observam alterações nos canais $\mathrm{N} \geq 2$. Considera-se também que a elevação no uso de canais N1 se dá fundamentalmente devido ao PAA se enquadrar nesse grupo. Além disso, pôde-se observar um aumento de $14 \%$ no número total de canais utilizados, que passa de 96 para 110, indicando que o PAA se associa positivamente com o aumento da mercantilização dos agricultores dessa cooperativa.

Tabela 1 - Número total de ocorrências de uso dos canais, segundo cada nível, antes e depois do PAA e taxa de crescimento dos níveis - COOPERSOL, 2013.

\begin{tabular}{l|c|c|c}
\hline & \multicolumn{2}{|c|}{ Número total de ocorrências } & \multirow{2}{*}{ Taxa de crescimento } \\
\cline { 2 - 3 } & Antes PAA & Após o PAA & $-9 \%$ \\
\hline Canais N0 & 33 & 30 & $35 \%$ \\
Canais N1 & 49 & 66 & $0 \%$ \\
Canais N $\geq 2$ & 14 & 14 & $14 \%$ \\
\hline Total & 96 & 110 & \\
\hline
\end{tabular}

Fonte: Dados da pesquisa, 2013.

Considerando a participação relativa de cada nível de canal, antes e depois do PAA, têm-se os dados sumarizados na Tabela 2. Nela pode-se observar os dados de participação proporcional de cada nível de canal e a taxa de crescimento. 
No caso da COOPERSOL, pode-se observar que os canais N0, antes do PAA, representavam 34\% do total de canais utilizados pelos agricultores e, após o ingresso no programa, passam para $27 \%$, ocorrendo redução de $20 \%$. No caso dos canais N1, antes do PAA, eles representavam $51 \%$ do total de canais utilizados e após o PAA representam $60 \%$, ocorrendo incremento de $18 \%$. Em relação aos canais $\mathrm{N} \geq 2$, eles representavam $15 \%$ do total de canais utilizados antes do PAA e, após o ingresso no PAA, passaram para 13\%, representando um decréscimo de $13 \%$.

Em função disso, em termos de participação proporcional dos diferentes níveis de canais de comercialização, ou em termos da totalidade dos canais usados nas unidades de produção dos associados dessa cooperativa, considera-se que não se observam alterações substantivas, pois as alterações proporcionais se dão basicamente devido à adição do PAA nos canais N1. No caso dos agricultores da COOPOVEC ter-se-á uma situação bastante distinta.

Tabela 2 - Participação proporcional dos diferentes níveis de canais e respectivas taxas de crescimento, antes e depois do PAA - COOPERSOL, 2013.

\begin{tabular}{l|c|c|c}
\hline \multirow{2}{*}{} & \multicolumn{2}{|c|}{ Participação proporcional } & \multirow{2}{*}{ Taxa de crescimento } \\
\cline { 2 - 3 } & Antes PAA & Após o PAA & \\
\hline Canais N0 & $34 \%$ & $27 \%$ & $-20 \%$ \\
Canais N1 & $51 \%$ & $60 \%$ & $18 \%$ \\
Canais N $\geq 2$ & $15 \%$ & $13 \%$ & $-13 \%$ \\
\hline Total & $100 \%$ & $100 \%$ & - \\
\hline
\end{tabular}

Fonte: Dados da pesquisa, 2013.

$\mathrm{Na}$ Tabela 3 observa-se que, em relação aos canais N0, no caso dos sócios da COOPOVEC, tem-se uma associação positiva com o PAA, visto que, após o ingresso no programa, ocorreu crescimento de $18 \%$ no uso dos canais desse nível. Considerando os canais $\mathrm{N} 1$, após ingresso no PAA, observa-se uma ampliação significativa no uso desse tipo de canal, com um crescimento na ordem de $71 \%$. Esse crescimento ocorre fundamentalmente devido ao próprio PAA se enquadrar nesse grupo. Em relação aos canais $\mathrm{N} \geq 2$, observa-se que, após o ingresso no PAA, ocorreu decréscimo significativo no uso desse nível de canal, a uma magnitude de $67 \%$. Isso significa variação inversa da observada nos canais N0 e N1, representando uma associação negativa entre o ingresso no programa e o uso de canais desse nível ( $\mathrm{N} \geq 2$ ). Além disso, em termos globais, se verifica aumento de $7 \%$ no número total de canais utilizados pelo conjunto dos associados dessa cooperativa, que passou de 94 para 101, indicando que o PAA se associa positivamente com o aumento da mercantilização dos agricultores dessa cooperativa.

Tabela 3 - Número total de ocorrências de uso dos canais, segundo seus níveis, antes e depois do PAA e taxa de crescimento - COOPOVEC, 2014

\begin{tabular}{l|c|c|c}
\hline & \multicolumn{2}{|c|}{ Número total de ocorrências } & \multirow{2}{*}{ Taxa de crescimento } \\
\cline { 2 - 3 } & Antes PAA & Após o PAA & $18 \%$ \\
\hline Canais N0 & 32 & 38 & $71 \%$ \\
Canais N1 & 31 & 53 & $-67 \%$ \\
Canais N $\geq 2$ & 31 & 10 & $7 \%$ \\
\hline Total & 94 & 101 & \\
\hline
\end{tabular}

Fonte: Dados da pesquisa, 2014.

No caso da COOPOVEC, considerando as variações proporcionais nas taxas de uso dos diferentes grupos de canais, têm-se os dados sumarizados na tabela que segue. 
No caso dos associados da COOPOVEC, na Tabela 4, pode-se ver que os canais N0 representavam 34\% do total de canais utilizados antes do PAA e, após o ingresso nesse programa, passam para $38 \%$, ocorrendo variação positiva de $12 \%$. Os canais N1 representavam 33\% do total de canais usados antes do PAA e, após o ingresso nesse programa, passam para $52 \%$, ocorrendo variação positiva de $57 \%$. Os canais $\mathrm{N} \geq 2$, antes do PAA, representavam $33 \%$ do total de canais utilizados por esses agricultores e, após o ingresso no programa, passam a representar $10 \%$, revelando variação negativa de $70 \%$.

Tabela 4 - Participação proporcional dos diferentes níveis de canais e respectivas taxas de crescimento, antes e depois do PAA - COOPOVEC, 2014.

\begin{tabular}{l|c|c|c}
\hline & \multicolumn{2}{|c|}{ Participação proporcional } & \multicolumn{2}{c}{ Taxa de } \\
& Antes PAA & Após o PAA & $12 \%$ \\
\cline { 2 - 4 } & $34 \%$ & $38 \%$ & $57 \%$ \\
Canais N0 & $33 \%$ & $52 \%$ & $-70 \%$ \\
Canais N1 & $33 \%$ & $10 \%$ & - \\
\hline Total & $100 \%$ & $100 \%$ & \\
\hline
\end{tabular}

Fonte: Dados da pesquisa, 2014.

Portanto, no caso da COOPOVEC, pode-se apontar que o ingresso no PAA se associa positivamente com alterações na composição proporcional de uso dos distintos níveis de canais, ocorrendo aumento no uso dos canais N0 e N1 e redução, significativa, no uso dos canais $\mathrm{N} \geq 2$. Essa alteração proporcional não pode ser explicada apenas pela adição do PAA nos canais N1, revelando alterações substantivas na magnitude da proporção de uso de cada nível de canais, com incremento modesto nos canais N0, aumento substantivo nos canais N1 e decréscimo substantivo nos canais $\mathrm{N} \geq 2$.

A síntese das variações observadas no uso de cada nível de canal, após o ingresso no PAA, é apresentada no Quadro 2. Pode-se observar que é diferente a variação no uso dos distintos níveis de canais de comercialização nas duas cooperativas estudadas após o ingresso dos agricultores no PAA. Para os canais N0, no caso da COOPERSOL, a participação no programa implica redução e no caso da COOPOVEC, ocorre o aumento no uso de canais desse nível. Para os canais N1, ocorre aumento, em ambas cooperativas. Esse aumento, em certo sentido, era previsível, pois o PAA se inserir nesse nível. No caso dos canais $\mathrm{N} \geq 2$, o ingresso no programa se associa de forma diferente nas duas cooperativas. No caso da COOPOVEC, ocorre redução significativa e, no caso da COOPERSOL, não ocorrem alterações.

Quadro 2 - Tipo de variação ${ }^{6}$ no uso dos diferentes níveis de canais para a COOPERSOL - 2013 e a COOPOVEC - 2014, após o ingresso no PAA.

\begin{tabular}{|c|c|c|c|}
\hline \multirow{2}{*}{ COOPERSOL } & \multicolumn{3}{|c|}{ Variação por nível de canal } \\
\cline { 2 - 4 } & No & N1 $\geq 2$ \\
\hline COOPOVEC & - & + & $=$ \\
\hline
\end{tabular}

Fonte: Dados da pesquisa, 2013 e 2014.

Como argumentou-e anteriormente, nos canais N0 os agricultores possuem maior controle e poder. Por isso, considera-se que são os canais em que os agricultores possuem "alta" autonomia, por estarem numa posição mais favorável nos processos de comercialização. Por outro lado e em outro extremo, nos canais $\mathrm{N} \geq 2$, os agricultores se encontram em uma posição menos favorável. Por isso, considera-se que nesses canais os

${ }^{6}$ Se positiva $(+)$, se negativa $(-)$ e sem variação $(=)$. 
agricultores possuem "baixa" autonomia. Os canais N1 serão considerados de "média" autonomia, por estarem em posição intermediária.

Tomando essa classificação dos distintos graus de autonomia como instrumento analítico, no Quadro 3, tem-se a síntese das observações feitas sobre o tipo de variação nos graus de autonomia comercial dos agricultores de cada cooperativa.

Considerando os dois extremos da classificação dos graus de autonomia, conforme Quadro 3, pode-se afirmar que, no caso da COOPOVEC, o ingresso no PAA se associa favoravelmente ao aumento da autonomia comercial dos agricultores, visto que o ingresso nesse programa se associa positivamente com o aumento no uso de canais de alta autonomia e com a redução no uso de canais de baixa autonomia. No caso da COOPERSOL não se verifica esse aumento da autonomia comercial, devido à diminuição no uso de canais de alta autonomia e a não alteração no nível de uso de canais de baixa autonomia.

Quadro 3 - Variação nos graus de autonomia comercial dos agricultores após o ingresso no PAA COOPERSOL, 2013 e COOPOVEC, 2014.

\begin{tabular}{|c|ccc|}
\hline \multirow{2}{*}{ COOPERSOL } & \multicolumn{3}{|c|}{ Variação nos graus de autonomia } \\
\cline { 2 - 4 } & Alta & Média & Baixa \\
\hline COOPOVEC & Diminui & Aumenta & Não altera \\
\hline
\end{tabular}

Fonte: Dados da pesquisa, 2013 e 2014.

\section{CONSIDERAÇÕES FINAIS}

Este artigo teve como tema os mercados institucionais. O objeto específico de análise foi o PAA. O objetivo foi identificar possíveis associações entre o ingresso no PAA e alterações nos níveis de uso dos distintos tipos de canais de comercialização para, desde aí, analisar a relação entre a inserção nesse programa e a variação na autonomia comercial dos agricultores familiares. Ao longo do artigo, analisou-se o caso de duas cooperativas localizadas na região Fronteira Noroeste do Rio Grande do Sul, considerando três hipóteses de estudo.

A primeira hipótese afirmava que a inserção no PAA implicaria na ampliação dos processos de mercantilização. Esse processo de ampliação da mercantilização foi operacionalizado, em termos de pesquisa, como o aumento no número de canais de comercialização utilizados pelos agricultores. Segundo esta apreciação, conforme os dados analisados, para o caso da COOPERSOL, essa hipótese é verdadeira, pois se observou uma clara tendência de aumento no número total de canais de comercialização utilizados para a maioria dos agricultores consultados. No caso da COOPOVEC, esta hipótese não pode ser aceita como verdadeira, em função de termos aumento no número total de canais utilizados apenas para uma parte dos agricultores e para outra parte expressiva dos agricultores, observase diminuição nesse número.

A segunda hipótese de trabalho preconizava que o PAA concorreria com outros canais de comercialização dos agricultores produzindo mudanças em suas dinâmicas comerciais, 
gerando alterações substantivas nos tipos de canais utilizados e na magnitude de utilização desses canais. Segundo esta apreciação, para o caso da COOPERSOL, essa hipótese não é verdadeira, pois não ocorreram alterações substantivas na dinâmica comercial, devido ao PAA se agregar a um conjunto de canais já em uso, sendo considerado como "mais um canal", de menor importância, não tendo muita relevância para a renda das famílias e não se associando com mudanças significativas nas taxas de uso dos canais já utilizados antes do ingresso no PAA. No caso da COOPOVEC, essa segunda hipótese foi confirmada, em função de se observar mudanças substantivas nos tipos de canais utilizados e alterações significativas na proporção de uso dos diferentes tipos de canais.

Considerando as duas primeiras hipóteses, pode-se afirmar que, as alterações nas dinâmicas comerciais ocorridas após o ingresso no PAA, no caso da COOPERSOL, são de caráter mais quantitativo e, no caso da COOPOVEC, também possuem caráter qualitativo. Isso fica mais evidente ao analisar-se a última hipótese de estudo.

A terceira hipótese apresentada em nossa pesquisa afirmava que ocorreria aumento na autonomia comercial dos agricultores após ingresso no PAA, com aumento no uso de canais de comercialização onde os agricultores possuem maior poder e controle e, paralelamente, ocorreria diminuição no uso de canais onde os agricultores apresentam menor poder e controle. Segundo nossa apreciação, para os associados da COOPERSOL, essa hipótese não é verdadeira. No caso dessa cooperativa o ingresso no PAA gera redução no uso de canais em que os agricultores possuem maior poder e controle e, ao mesmo tempo, não gera alterações no uso de canais em que os agricultores possuem menor poder e controle. Ou seja, no caso dessa cooperativa, o ingresso no PAA não gera alterações no grau de autonomia comercial dos agricultores. No caso da COOPOVEC considera-se que essa hipótese foi confirmada. Entre os associados dessa cooperativa observa-se que o ingresso no PAA gera crescimento no uso de canais onde os agricultores possuem maior poder e controle e, ao mesmo tempo, gera redução no uso de canais onde os agricultores possuem menor poder e controle. Ou seja, no caso dessa cooperativa considera-se que o ingresso no PAA se associa positivamente com o aumento da autonomia comercial dos agricultores.

No caso da COOPERSOL, o ingresso no PAA não implica alterações qualitativas na dinâmica comercial. O que ocorre é uma alteração de caráter mais quantitativo, pois se observa a ampliação do processo de mercantilização, devido ao aumento no número dos canais de comercialização utilizados pela maioria dos agricultores, sem variações significativas na proporção de uso dos diferentes níveis de canais. No caso dessa cooperativa, nos níveis dos canais em que ocorreram alterações nas taxas de uso, observa-se que essas variações não foram tão altas, o que significa a manutenção de certa estabilidade no uso dos demais canais, aos quais o PAA é agregado, sem gerar exclusão de outros canais de venda. O único canal que tem ampliação do uso, após o ingresso no PAA, é o de vendas para o PNAE. Nestes termos e considerando o conjunto dessas observações, conclui-se que a inserção no PAA não implica a ampliação da autonomia comercial desses agricultores.

Já no caso da COOPOVEC, o ingresso no PAA implica em alterações significativas na dinâmica comercial dos agricultores. Em termos quantitativos não houve alterações tão significativas, não se observando ampliação da mercantilização. $O$ que se observou foram mudanças de caráter mais qualitativo, com alterações substantivas na proporção de uso dos diferentes níveis de canais. Neste sentido, observa-se aumento no uso de canais onde os agricultores têm maior poder e controle e diminuição significativa no uso de canais em que os 
agricultores possuem menor poder e controle. Por isso, considera-se que o PAA se associa positivamente em relação ao aumento da autonomia comercial desses agricultores.

Com base na análise apresentada, pôde-se concluir que o PAA se insere de modo diverso em termos de variação da autonomia comercial dos agricultores nas duas cooperativas consideradas. Numa das cooperativas (COOPOVEC) o ingresso no programa se associa positivamente com o aumento no uso de canais pertencentes ao nível em que os agricultores possuem maior autonomia e redução no uso de canais pertencentes ao nível em que os agricultores possuem menor autonomia, donde se conclui que o ingresso no PAA contribui positivamente para a ampliação da autonomia comercial dos agricultores associados a essa cooperativa. No caso da outra cooperativa (COOPERSOL) não se observa esse mesmo fenômeno, donde se conclui que o ingresso no PAA não se associa com a ampliação da autonomia comercial dos agricultores a ela associados. As razões que explicam essas variações, em sentido tão diverso, carecem de investigação mais detalhada e serão buscadas na continuidade dos estudos.

\section{REFERÊNCIAS}

ALVES, E.; ROCHA, D. P. Ganhar tempo é possível. In: GASQUES, J; VIEIRA FILHO, J. E. R.; NAVARRO, Z. A agricultura brasileira: desempenho recente, desafios e perspectivas. Brasília: IPEA/MAPA, 2010.

BARBETTA, P. A. Estatística aplicada às ciências sociais. Florianópolis: Ed. UFSC, 2011.

CAPORAL, F. R. Em defesa de um Plano Nacional de Transição Agroecológica: compromisso com as atuais e nosso legado para as futuras gerações. 2009. Manuscrito.

CIRINO, J. F. et al. Utilização de um sistema de informação gerencial para a gestão de projetos do Programa de Aquisição de Alimentos em organizações sociais do Estado de Minas Gerais: possibilidades e dificuldades. Espacios, Caracas, v. 37, n. 06, p. 21, 2016.

CONTERATO, M. A. et al. Mercantilização e mercados: a construção da diversidade da agricultura na ruralidade contemporânea. In: SCHNEIDER, S.; GAZOLLA, M. (Org.). Os atores do desenvolvimento rural: perspectivas teóricas e práticas. Porto Alegre: Editora da UFRGS, 2011. p. 67-89.

CONTERATO, Marcelo Antonio. A mercantilização da agricultura familiar do Alto Uruguai/RS: um estudo de caso do município de Três Palmeiras. 2004. Dissertação (Mestrado em Desenvolvimento Rural) - Programa de Pós-Graduação em Desenvolvimento Rural, Faculdade de Ciências Econômicas, Universidade Federal do Rio Grande do Sul, Porto Alegre, 2004.

CONTERATO, M. A. Dinâmicas regionais do desenvolvimento rural e estilos de agricultura: uma análise a partir do Rio Grande do Sul. 2008. Tese (Doutorado em Desenvolvimento Rural) - Programa de Pós-Graduação em Desenvolvimento Rural, 
Faculdade de Ciências Econômicas, Universidade Federal do Rio Grande do Sul, Porto Alegre, 2008.

CORADIN, C.; SOUZA, R. S. Os Quilombolas e o Programa de Aquisição de Alimentos (PAA) no Vale do Ribeira Paraná: diversidades culturais, enquadramentos burocráticos e ações dos mediadores técnicos e sociopolíticos. Revista NERA, Presidente Prudente, Ano 18, n. 26 - Edição especial, p. 122 - 146, 2015.

COSTA, B. A. L. et al. As Cooperativas de Agricultura Familiar e o Mercado de Compras Governamentais em Minas Gerais. RESR, Piracicaba, v. 53, n. 01, p. 109-126, 2015.

FOOD AND AGRICULTURE ORGANIZATION OF UNITED NATION. The State of Food and Agriculture 2015: Social protection and agriculture: breaking the cycle of rural poverty. FAO: 2015.

FREITAS, M. F. L. Agricultura familiar e políticas de redução da pobreza rural: uma análise do perfil dos agricultores participantes do Programa de Aquisição de Alimentos (PAA) no município de Tunas do Paraná, Vale do Ribeira - PR. 2011. Monografia (Especialista em Desenvolvimento Regional) - Programa de Pós-Graduação em Desenvolvimento Regional, Departamento de Economia Rural e Extensão, Setor de Ciências Agrárias, Universidade Federal do Paraná. Curitiba, 2011.

GAZOLLA, M.; PELEGRINI, G. Novos mercados da agricultura familiar: o caso das pequenas unidades agroindustriais produtoras de alimentos. In.: SCHNEIDER, S.;

GAZOLLA, M. (Org.). Os atores do desenvolvimento rural: perspectivas teóricas e práticas. Porto Alegre: Editora da UFRGS, 2011. p. 133-150.

GRANOVETTER, M. Acção económica e estrutura social: o problema da incrustação. In: MARQUES, R.; PEIXOTO, J. (Org.). A nova sociologia económica: uma antologia. Oeiras: Celta, 2003. p. 69 - 102.

GRAZIANO DA SILVA, J. A nova dinâmica da agricultura brasileira. Campinas: Ed. UNICAMP, 1996.

GRISA, C. As redes e as instituições do Programa de Aquisição de Alimentos (PAA).

Revista Brasileira de Gestão e Desenvolvimento Regional, Taubaté, v. 6, n. 2, p. 97 - 129, 2010.

GRISA, C. Políticas públicas para a agricultura familiar no Brasil: produção e institucionalização das ideias. 2012. Tese (Doutorado em Desenvolvimento, Agricultura e Sociedade) - Programa de Pós-Graduação de Ciências Sociais em Desenvolvimento, Agricultura e Sociedade, Instituto de Ciências Humanas e Sociais, Universidade Federal Rural do Rio de Janeiro, Rio de Janeiro, 2012.

GRISA, C. et al. O Programa de Aquisição de Alimentos (PAA) em perspectiva: apontamentos e questões para o debate. Rio de Janeiro, 2009. Relatório OPPA.

HOLANDA, D. R. Desenvolvimento rural sustentável: o caso do Programa de Aquisição de Alimentos (PAA) no Território da Cidadania Vales do Curu e Aracatiaçu - CE. 2012. 
Dissertação (Mestrado em Economia Rural) - Programa de Pós-Graduação em Economia Rural, do Centro de Ciências Agrárias da Universidade Federal do Ceará, Fortaleza, 2012.

LONG, N. Sociología del desarrollo: una perspectiva centrada en el actor. México: Ciesas, 2007.

MARINHO, Marisson de Melo. O Programa de Aquisição de Alimentos e a construção social de mercados: estudo de caso da COPERTERRA. 2014. Dissertação (Mestrado em Extensão Rural) - Programa de Pós-Graduação em Extensão Rural, Centro de Ciências Rurais, Universidade Federal de Santa Maria, Santa Maria, 2014.

MARSDEN, T. et al. Beyond agriculture? Regulating the new rural spaces. Jornal of Rural Studies, London, v. 11, n. 3, p. 285 - 296, 1995.

MATTEI, L. O papel e a importância da agricultura familiar no desenvolvimento rural brasileiro contemporânea. Revista de Economia do Nordeste, número especial Agricultura Familiar, 2014.

MAZOYER, M.; ROUDART, L. História das agriculturas no mundo: do neolítico à crise contemporânea. São Paulo: UNESP; Brasília: NEAD, 2010.

MENEZES, F. et al. Abastecimento alimentar e compras públicas no Brasil: um resgate histórico. Brasília: WFP, 2015.

MINAYO, M. C. S. Pesquisa social: teoria, método e criatividade. Petrópolis: Vozes, 2012.

NIEDERLE, P. A. et al. Estilos de agricultura: capturando a diversidade do rural contemporâneo. In: CONTERATO, M. et al. (Org.). Pesquisa em desenvolvimento rural: aportes teóricos e proposições metodológicas. Porto Alegre: Editora da UFRGS, 2014. p. 205 -225 .

NIEDERLE, P. A. Mercantilização, estilos de agricultura e estratégias reprodutivas dos agricultores familiares de Salvador das Missões, RS. 2007. Dissertação (Mestrado em Desenvolvimento Rural) - Programa de Pós-Graduação em Desenvolvimento Rural, Faculdade de Ciências Econômicas, Universidade Federal do Rio Grande do Sul, Porto Alegre, 2007.

OLIVEIRA, A. L. A. de; BERGAMASCO, S. M. P. P. Análise do Programa de Aquisição de Alimentos (PAA) no município de Paranaíta, Estado de Mato Grosso, Brasil. Revista da Universidade Vale do Rio Verde, Três Corações, v. 12, n. 1, p. 925-935, jan./jul., 2014.

PLOEG, J. D V. D. Camponeses e impérios alimentares: lutas por autonomia e sustentabilidade na era da globalização. Porto Alegre: Editora da UFRGS, 2008.

PLOEG, J. D V. D. O modo de produção camponês revisitado. In: SCHNEIDER, S. (Org.). A diversidade da agricultura familiar. 2.ed. Porto Alegre: UFRGS, 2009. p. 15 - 56.

PLOEG, J. D. van der.; LONG, N. Born from within: practice and perspectives of endogenous rural development. Assen: Van Gorcun, 1994. 
ROTOLI, L. U. M.; SCALCO, A. R. Evolução da agricultura suportada pela comunidade como um mecanismo de comercialização no Brasil. Espacios, Caracas, v. 37, n. 19, p. 10, 2016.

SALGADO, R. J. dos S. F.; DIAS, M. M. Análise da influência do Programa de Aquisição de Alimentos (PAA) sobre a qualidade de vida de agricultores familiares do município de Viçosa/MG. Perspectivas em Políticas Públicas, Belo Horizonte, v. 6, n. 11, p. 65 - 91, jan./jun., 2013.

SALGADO, R. J. S. F. et al. Estimação da cobertura do Programa de Aquisição de Alimentos para os municípios brasileiros. In.: CONGRESSO DA SOCIEDADE BRASILEIRA DE ECONOMIA, ADMINISTRAÇÃO E SOCIOLOGIA RURAL, 53, João Pessoa, 2015. Anais... João Pessoa: SOBER, 2015.

SCHNEIDER, S. Reflexões sobre diversidade e diversificação: agricultura, formas familiares e desenvolvimento rural. RURIS, Campinas, v. 4, n. 1, p. 85 - 132, 2010.

SCHNEIDER, S.; ESCHER, F. El concepto de agricultura familiar en América Latina. In: CRAVIOTTI, C. (Org.). Agricultura familiar en Latinoamérica: continuidad, transformaciones y controversias. Buenos Aires: CICCUS, 2014. p. 25 - 56.

SCHNEIDER, S.; GAZOLLA, M. Os atores do desenvolvimento rural: perspectivas teóricas e práticas. Porto Alegre: Editora da UFRGS, 2011.

SCHNEIDER, S.; NUNES, E. M.; Reestruturação agrícola, instituições e desenvolvimento rural no nordeste: a diversificação da agricultura familiar do Polo Açu-Mossoró (RN).

Revista Economia NE, Fortaleza, v. 44, n. 3, p. 601 - 626, 2013.

SOUZA-ESQUERDO, V. F. de; BERGAMASCO, S. M. P. P. Análise sobre o acesso aos programas de políticas públicas da agricultura familiar nos municípios do Circuito das Frutas (SP). RESR, Piracicaba, v. 52, Supl. 1, p. 205 - 222, 2014.

TONNEAU, J. P.; SABOURIN, E. Agricultura familiar: integração entre políticas públicas e dinâmicas locais: ensinamentos a partir de casos. Porto Alegre: Editora da UFRGS, 2007.

WAQUIL, P. D. et al. Mercados e comercialização de produtos agrícolas. Porto Alegre: UFRGS, 2010.

WANDERLEY, M. N. B. O mundo rural como um espaço de vida. Porto Alegre: UFRGS, 2009.

Artigo recebido em: 03/04/2017

Artigo aprovado em: 01/05/2017 